\title{
The Value Transformation Framework: Applied to Diabetes Control in Federally Qualified Health Centers
}

\author{
Cheryl Modica (D) \\ Joy $\mathrm{H}$ Lewis $^{2}$ \\ R Curtis Bay ${ }^{3}$
}

'National Association of Community Health Centers, Bethesda, MD, USA; ${ }^{2}$ Medicine and Public Health, SOMA Department of Public Health, School of Osteopathic Medicine in Arizona, A.T. Still University, Meza, AZ, USA;

${ }^{3}$ Department of Interdisciplinary Health Sciences, Arizona School of Health Sciences, A.T. Still University, Mesa, AZ, USA
Correspondence: Cheryl Modica National Association of Community Health Centers, Inc., 750I Wisconsin Avenue, Suite II00W, Bethesda, MD, 208I4, USA

Tel + I 30I 310 2250

Email cmodica@nachc.org
Introduction: Diabetes and pre-diabetes impact more than 114 million Americans. Federally qualified health centers (FQHCs) provide care to some of the most high-risk and underinsured individuals throughout the US, twenty-one percent of whom report being told they have diabetes, compared to $11 \%$ of the general adult population. It is widely agreed our health care system requires a transformation to effectively address diabetes and its complications.

Objective: By applying the Value Transformation Framework (VTF) in health centers, the National Association of Community Health Centers (NACHC) aims to show improvements in diabetes control. This systematic strategy to transform the way health centers operate can lead to improvements in health outcomes, patient and staff experiences, costs, and equity (Quintuple Aim). Special attention is paid to the health centers' infrastructure, people systems and care delivery systems.

Methods: Evidence-based diabetes interventions, the learning community model, and the VTF were used together to drive system improvements and activate proven diabetes control practices within eight health centers. Multidisciplinary teams at select health centers in Georgia and Iowa, with their partner primary care associations, participated in this NACHCled quality improvement project.

Results: During the one-year intervention (January 2017-December 2017), the mean raw percentage of patients with HbA1c Poor Control decreased from 50.9\% (range, 23.7-70.4\%) in January to $27.5 \%$ (range, $13.6-37.4 \%$ ) in December. This represents a relative improvement in diabetes control of $46 \%$. The 1-year-intervention data also showed trends in the desired direction with statistically significant improvements related to the following interventions: a formal written clinical policy, standing orders, patient recall/outreach, performance data shared at the provider/team-level, and performance data shared at the site/ organization level.

Conclusion: A conceptual model focused on transforming health center systems, organized by the NACHC Value Transformation Framework and supported by a strong learning community, can lead to better diabetes control outcomes among patients seen at health centers.

Keywords: vulnerable populations, hemoglobin A1c, quality improvement, health systems, interdisciplinary care

\section{Plain Language Summary}

The National Association of Community Health Centers, Inc. (NACHC) Quality Center developed the Value Transformation Framework (VTF) to help health centers improve 
outcomes such as diabetes control by changing or transforming the systems in which they operate. This model translates research, proven solutions, and promising practices into clear and practical steps that health centers can use to achieve valuedriven care. The authors report diabetes control improvements for a cohort of health centers that applied NACHC's VTF. The action steps taken by health centers participating in this quality improvement project are doable activities. They can be applied by other health centers across the country. Some of the most effective system changes include putting standing orders in place and sharing responsibilities for patient care among a wide group of staff across the organization. The impact of diabetes in our nation, particularly among health center patients, is substantial. Identifying strategies to change health center systems in ways that improve diabetes control is critically important. The authors demonstrated that implementing NACHC's VTF can provide health centers with a practical and actionable approach to health center systems change as a means to achieve significant improvements in diabetes control.

\section{Introduction}

The health, social, and economic impacts of diabetes are growing, as the number of adults diagnosed with diabetes increases and is expected to continue rising as the US population ages and becomes more overweight. ${ }^{1}$ Approximately $11 \%$ of the US population, or 34.2 million Americans, have diabetes. ${ }^{2}$ Approximately $35 \%$ of Americans ( 88 million adults) have been diagnosed with prediabetes, meaning their blood glucose levels are higher than normal but not yet at the level to be diagnosed with type 2 diabetes. ${ }^{2}$ Many of these individuals (15-30\%) will develop Type 2 diabetes within 5 years if they do not lose weight or increase their level of physical activity., ${ }^{3,4}$ While $11 \%$ of the adult population in the US report being told they have diabetes, this estimate is $21 \%$ among patients receiving care in federally qualified health centers (hereafter referred to as "health centers"). ${ }^{5}$ The burden diabetes places on individuals and the health care system, particularly at health centers which provide care to vulnerable individuals regardless of their ability to pay, is enormous. The majority of the approximately 30 million patients who receive primary care at one of the 13,000 health centers nationwide live below the federal poverty level. ${ }^{6}$ Many health center patients face social and environmental risk factors that affect their health and well-being.

Health centers provide high quality chronic care, even for their high-risk, complex patient populations. In fact, vulnerable patients with high burdens of chronic disease receive care at health centers that meets or exceeds national practice standards ${ }^{7}$ at lower costs. ${ }^{8}$ Health centers are estimated to save the US health care system $\$ 24$ billion annually. ${ }^{8}$

Therefore, improving diabetes control among health center patients can have far-reaching effects on the overall health care system. People with diabetes are more likely to experience serious health complications, including heart disease and stroke. Diabetes mellitus, for example, can lead to kidney failure, amputations of lower limbs, and blindness. ${ }^{9}$ Diabetes is the seventh most prominent cause of death in the U.S. ${ }^{2,10}$ Minority populations, which health centers serve in large proportion, are diagnosed with diabetes at higher rates: $14.7 \%$ of American Indians/Alaska Natives, $12.5 \%$ of Hispanics, $11.7 \%$ of non-Hispanic blacks, and $9.2 \%$ of Asians, compared with $7.5 \%$ of non-Hispanic whites. ${ }^{2}$

For adults in the US age 20 years and older, diabetes ranks highest in healthcare spending among all disease categories. $^{11}$ In 2017, diabetes care cost an estimated $\$ 327$ billion in the US, including \$237 billion for direct medical costs and $\$ 90$ billion in indirect costs. Indirect costs are related to time lost from work, disability, or early death. $^{12}$ The cost of providing medical care to patients with diabetes increases significantly for every $1 \%$ increase in Hemoglobin A1c (HbA1c) above HbA1c of $7 \%{ }^{13}$

Tackling a complex and debilitating chronic condition such as diabetes requires a multi-faceted, multi-system approach. It is widely agreed that effectively addressing the problem of diabetes requires a transformation of health care systems. ${ }^{14}$ NACHC's Quality Center developed the Value Transformation Framework (VTF) to guide systems change in health centers so they can improve health outcomes, patient and staff experiences, costs, and health equity for conditions such as diabetes (Figure 1). ${ }^{15}$ This evidence-based model translates research, proven solutions, and promising practices into manageable steps health centers can take to shift their operational systems towards the delivery of value-driven care.

The NACHC Quality Center worked with a cohort of health centers and their partners to apply the VTF in a quality improvement and transformation project that included, as one of its measures, improved diabetes control. Below are descriptions of each organization engaged in this project:

- National Association of Community Health Centers (NACHC): The national organization dedicated to improving health care through the Community Health Center model.

- Health Centers: Community-based health care providers that offer primary care to medically underserved 


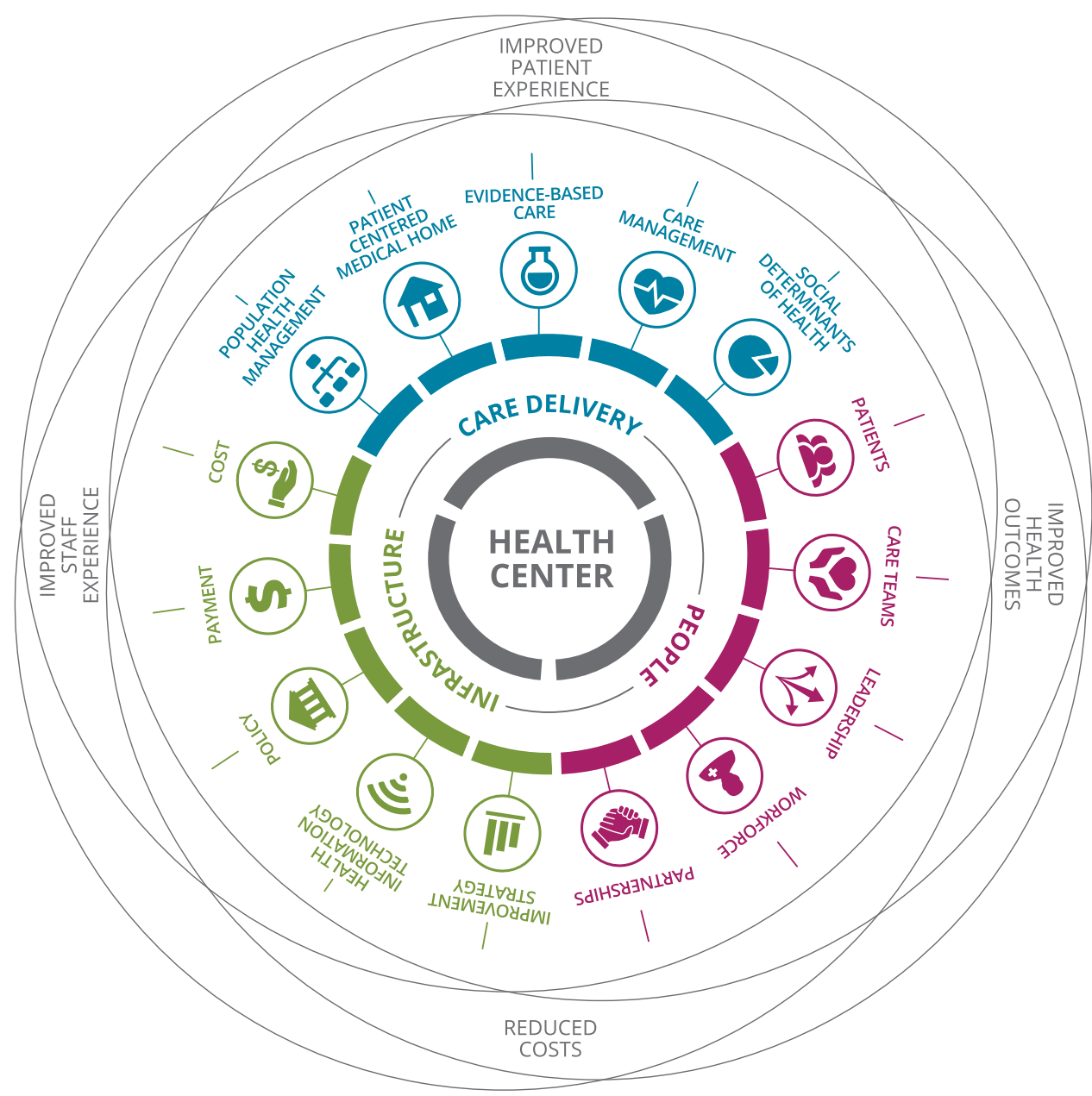

Figure I Value transformation framework.

populations regardless of their insurance or ability to pay. Health centers are funded through the Health Resources and Services Administration (HRSA) Health Center Program.

- Health Center-Controlled Networks (HCCNs): Groups of health centers working together to improve health care access and quality at lower costs with health information technology improvements and sharing best practices.

- Primary Care Associations (PCAs): State or regional health center membership organizations. They provide technical assistance and training to health centers.

\section{Improving Diabetes Outcomes with Multicomponent Interventions}

Literature reviews and data from diabetes interventions and quality improvement (QI) efforts show effective diabetes care requires a multifactorial approach that relies on changes in organizational infrastructure, care delivery, and people systems. ${ }^{14,16-19}$ One analysis concluded that interventions should focus on patient education, training in behavioral change for physicians and other patient care providers, rethinking local care delivery systems, and improving access to care with structural and financial adjustments. ${ }^{20}$ Other investigators who explored healthcare interventions that reduce diabetes health disparities also found evidence to support the use of targeted interventions for patients (for example, with culturally-tailored programs); one-on-one feedback and education for providers, and adjusting care delivery systems by using nurse case managers and nurse clinicians. ${ }^{21}$

Data suggest greater success in lowering $\mathrm{HbAlc}$ through the use of multi-level quality improvement (QI) strategies that target both the care delivery system and the patient. ${ }^{14,18}$ One investigation that examined a portfolio of 
11 QI strategies, found most produced only small-tomodest improvements in glycemic control. However, when care teams changed to include case management, the greatest improvements were seen - especially when case managers could adjust medications through the use of standing orders without waiting for physician approval. ${ }^{14}$ Another study found case management interventions were most effective when case managers could make independent medication changes and could work with multidisciplinary, interactive teams. ${ }^{18}$ In these studies, simply adding a team member was not effective. Changes to the structure or organization of the primary health care team were also important. For example, responsibilities for "shared care" are required with the addition of a new team member. This means routine activities for patient care could be conducted by staff other than the primary physician, such as a physician assistant, nurse specialist, pharmacist, nutritionist, podiatrist or other specialist. Expanding or revising professional roles was found to be most effective. ${ }^{14,18}$

\section{The Value Transformation Framework (VTF)}

NACHC's Quality Center developed the VTF as a model that supports systems change for health centers, so they can transform from a volume- to a value-driven model of care delivery. Value, long defined as the Triple Aim (better health outcomes, better patient experience, and reduced costs), has expanded in recent years to include improvements in staff experience ${ }^{15,22,23}$ and equity, thereby increasing the definition of value to include all Quintuple Aims.

The VTF conceptually organizes evidence-based interventions designed to help health centers reach their Quintuple Aims. It focuses on enhancements to a health center's infrastructure, people, and delivery systems (known in the Framework as "Domains"). ${ }^{24}$ The Framework divides the Domains into 15 "Change Areas" with more concrete interventions and recommended action steps (Figure 2). The model packages and directs evidence-based action for each Change Area with the understanding that application across many Change Areas can affect overall systems change.

\section{Methods}

This project sought to improve diabetes control among patients in participating health centers by applying evidence-based interventions outlined in the Value
Transformation Framework across multiple health center systems. The approach included a three-part strategy. It combined (1) the VTF; (2) proven interventions for systems change, driven by evidence; and (3) the Learning Community Model $^{25-27}$ to achieve health center system improvements. The premise was that system improvements, driven by tested strategies, could lead to improvements across multiple clinical measures. These measures include, colorectal and cervical cancer screening and improved screening and control of diabetes, hypertension, obesity, and depression.

In 2017, NACHC served as the project lead working with the Georgia and Iowa PCAs, and four health centers in each state. There were six urban and two rural health centers participating in the application of the $\mathrm{VTF}^{28}$ (Table 1). ${ }^{15}$

Each health center identified a lead site for interventions. The analysis and results reported here relate to the health centers' intervention sites ("health centers"). The project sought to answer the following questions:

1. Can evidence-based system improvements, when coupled with diabetes-specific interventions in a learning community model, result in better diabetes control?

2. Is application of the VTF associated with a decrease in the proportion of adult health center patients with diabetes who have HbA1c Poor Control (defined as most recent $\mathrm{HbAlc}>9$, the most recent $\mathrm{HbAlc}$ result is missing, or no $\mathrm{HbAlc}$ tests performed or documented during the measurement period)?

3. Which interventions (reflecting VTF "Change Areas") were affiliated with improved diabetes control?

This project was submitted to, and reviewed by, the A.T. Still University (ATSU, Arizona) Institutional Review Board (IRB) who determined it did not fall under the jurisdiction of the Board.

\section{Quality Improvement (QI) and VTF Approach}

This project embedded activities to improve diabetes control within larger transformation efforts. The project team supported participant health centers as they applied elements of the Value Transformation Framework's Change Areas. Focus areas included: (1) Leadership, (2) Population Health Management, including Risk 


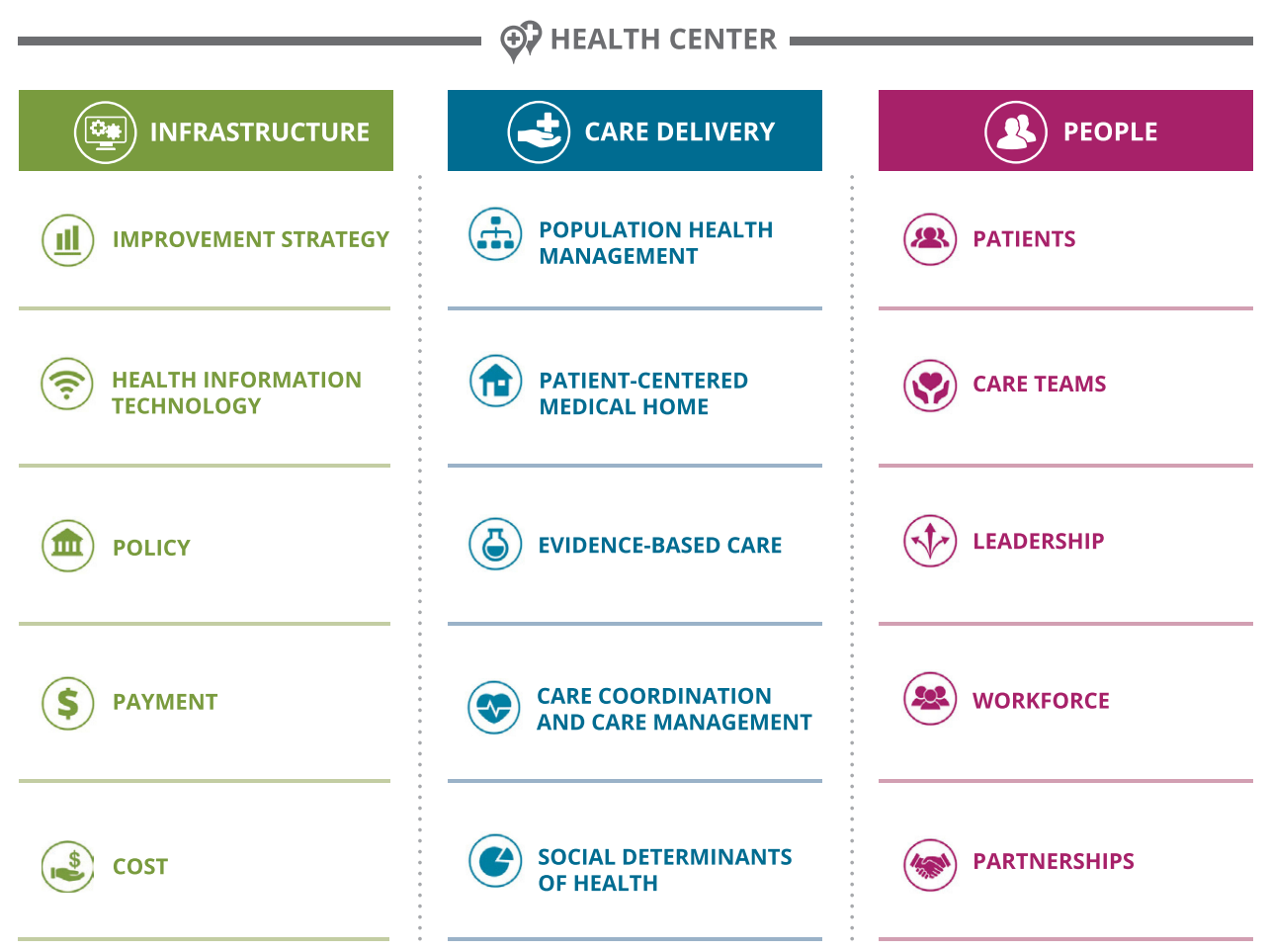

Figure 2 Value transformation framework change areas.

Stratification, (3) Models of Care, (4) Care Management, (5) Care Teams, and (6) Patient Engagement.

The project learning community model included the following components:

- The selection of multi-disciplinary teams at the health center level.

- Coaching in transformation activities by NACHC and the state PCA/HCCN partners.

- Evidence-based "action steps" found in Action Guides of the Value Transformation Framework.

- Improvement activities built on Plan-Do-Study-Act (PDSA) cycles. $^{29}$

Table I Profile of 8 Participating Health Centers (6 Urban, 2 Rural)

\begin{tabular}{|l|c|c|}
\hline $\begin{array}{l}\text { UDS } 2016 \text { (Uniform Data } \\
\text { Systems) Data Element* }\end{array}$ & Average & Range \\
\hline Number of patient visits & 17,496 & $2500-38,000$ \\
\% Racial/ethnic minorities & $49 \%$ & $5-77 \%$ \\
\% Best served in another language & $11 \%$ & $<1 \%-25 \%$ \\
\% Uninsured & $30 \%$ & $5-54 \%$ \\
Baseline HbAlc Poor Control & $39 \%$ & $16-64 \%$ \\
\hline
\end{tabular}

Note: *Organizational-level UDS data rounded to the nearest whole $\%$ or hundreds.

\section{Study Setting}

Eight participating health centers identified their care team and project leaders. These teams were comprised of: a provider, a nurse care manager, a representative from QI or health information technology (HIT), and, in some cases a member of the finance team. Health centers were given funding to aid in the hiring of a nurse care manager. Most health centers filled the care manager role with a Registered Nurse. In one case, a foreign-trained medical doctor was hired to serve in this role. Care managers were encouraged to use population health approaches to develop or expand the health center's care management model. They also managed abnormal lab results and coordinated referral tracking and follow-up.

\section{Intervention}

The intervention began in January 2017 and ended in December 2017 at all eight health centers. Health center teams and PCA/HCCN QI staff participated, in-person, in project launch meetings on January 31, 2017 in Iowa and March 2, 2017 in Georgia. The NACHC Principal Investigator (PI) presented the project plan and explained: QI fundamentals, the VTF, interactive workflow mapping, evidence-based interventions for systems-change, population health approaches/risk stratification, models of care, and reporting requirements. Each team used their time at 
these meetings to review current patient-visit workflows and outline potential areas to apply systems-change interventions. Health center priorities, staffing, and resources influenced decisions related to which interventions to apply.

Using VTF Action Guides, the project team coached health center teams to first complete a risk stratification process, enabling them to divide their patient population by risk category. Then, health center teams defined models of care to serve each risk category. Throughout the year, the project team supported health center teams as they implemented evidenced-based action steps outlined in VTF Action Guides to achieve systems-level changes. The project team also helped guide health centers as they collected data and evaluated their results. The Action Guides provided each health center team with core content in the transformation areas of: (1) Leadership; (2) Population Health: Risk Stratification and Models of Care; (3) Care Management; (4) Care Teams; and (5) Patient Engagement.

\section{Data Collection}

Before the program launched, and again at the end of the intervention year, the project team conducted organizational assessments with each participating health center. Organized by the three Value Transformation Framework Domains, these pre- and post-assessments captured data on organizational changes and interventions implemented by the health centers. Interventions were classified as "present" or "absent" each month throughout the project's intervention year. Data were collected on "Diabetes: HbA1c Poor Control" as defined above, using guidelines outlined for health center federal reporting under the Uniform Data System (UDS) (Table 2). ${ }^{30}$

While FQHCs report UDS metrics annually to the HRSA, participating health centers tracked and reported data each month for the project team. To ensure data validation, the project team provided coaching and support in the collection and reporting of measures. Monthly narrative reports on data and implementation were also prepared by the health center teams.

\section{Analysis}

Analyses were performed for data at the intervention site within each participating health center. Summary statistics including means (standard deviations) and counts (percentages), are provided as appropriate. Data were clustered by health center. An auto-regressive covariance matrix was used per month, and a generalized estimating equations (GEE) approach with a negative binomial link and robust variance estimates was used across the 1-year intervention period to model diabetes control. Rates of patients with diabetes with "HbA1c Poor Control" per month (defined as: "most recent HbA1c level is greater than 9.0\%", "the most recent HbAlc result is missing", or "no HbA1c tests performed or documented during the measurement period") were calculated by offsetting the monthly count of adult patients with HbA1c Poor Control by the monthly count of adult patients with diabetes who were seen.

Robust estimating procedures were used because individual patients could not be tracked from month-to-month, but undoubtedly, patients were counted multiple times during the 12-month interval. Robust estimating procedures provide consistent estimates of the covariance matrix for parameter estimates, even if the correlation structure for the model is mis-specified. The trend in HbA1c Poor Control over months was the outcome of interest. To evaluate the relationship of specific interventions to diabetes control rates, a GEE approach was used as above, and data were coded as " 0 " = no intervention and " $1 "=$ presence of intervention for each month and each site. Data were clustered by month, but month was not used as a predictor. Alpha $=0.05$ (two-tailed) was used as the criterion for statistical significance. Adjustments were not made for multiplicity. SPSS version 25 (IBM Corporation, Armonk, New York) was used for analysis.

Table 2 Monthly Diabetes Control per Uniform Data System (UDS) Instructions

\begin{tabular}{|c|c|c|c|}
\hline Measure & Measure Definition & Numerator & Denominator \\
\hline $\begin{array}{l}\text { Diabetes: } \\
\text { HbAlc } \\
\text { Poor } \\
\text { Control }\end{array}$ & $\begin{array}{l}\text { Percentage of patients } 18-75 \text { years of age } \\
\text { with diabetes who had hemoglobin Alc } \\
\text { (HbAlc) greater than } 9.0 \% \text { during the } \\
\text { measurement period. }\end{array}$ & $\begin{array}{l}\text { Patients whose most recent } \mathrm{HbAlc} \text { level } \\
\text { performed during the measurement year } \\
\text { is greater than } 9.0 \% \text {, the most recent } \\
\mathrm{HbAlc} \text { is missing, or there are no } \mathrm{HbAlc} \\
\text { tests performed or documented during } \\
\text { the measurement period. }\end{array}$ & $\begin{array}{l}\text { Patients } 18 \text { through } 75 \text { years of age with } \\
\text { diabetes with a medical visit during the } \\
\text { measurement year. Excludes patients with } \\
\text { a diagnosis of secondary diabetes due to } \\
\text { another condition. }\end{array}$ \\
\hline
\end{tabular}

Notes: Source: data from: Uniform Data System; Reporting instructions for 2017 Health Center Data. Bureau of Primary Health Care; 20I7. Available from: https://bphc. hrsa.gov/sites/default/files/bphc/datareporting/reporting/20I7udsreportingmanual.pdf. Accessed September 28, $2021{ }^{33 .}$ 


\section{Results}

During the one-year intervention (January 2017December 2017), the mean raw percentage of patients with HbA1c Poor Control decreased from 50.9\% (range, 23.7$70.4 \%$ ) in January to $27.5 \%$ (range, 13.6-37.4\%) in December (Table 3), test of trend across months, $\mathrm{p}<0.001$. This represents a relative improvement in diabetes control of $46 \%$.

When the data are combined across health centers, and the number of patients per site with HbA1c Poor Control was offset for the number of adult patients with diabetes seen that month, 5.6\% fewer patients, on average, per month had HbA1c Poor Control (95\% CI: -7.6, -3.3). All of the interventions, with the exception of "clinical champion" (a clinician leader whose actions and work call attention to improving diabetes care and outcomes) showed changes in the desired direction over the intervention period. Individual interventions that were significantly associated with improvements in diabetes control included:

- A formal written clinical policy $(\mathrm{p}=0.049)$

- Standing orders $(\mathrm{p}<0.001)$

- Patient recall/outreach $(\mathrm{p}<0.001)$

- Performance data shared at the provider/team-level $(\mathrm{p}=0.002)$

- Performance data shared at the site/organization level $(\mathrm{p}=0.008)$.

The clinical champion intervention was statistically significant but in the undesired direction.

Table 4 shows the duration of time (in months) the eight health centers had a given intervention in place. The mean number of interventions in place for each health center over the 12-month intervention period ranged from 0.9 to 7.1 .

\section{Discussion}

NACHC's Quality Center created a roadmap, the Value Transformation Framework, to support health center advancement toward the Quintuple Aim (better health outcomes, better patient and staff experiences, lower costs, and improved equity). In this transformation project, application of the VTF and a core set of evidence-based systems interventions, delivered in a Learning Community Model, showed statistically significant improvements in diabetes control.

The 1-year-intervention data showed trends in the desired direction with statistically significant improvements in diabetes control related to the following interventions: a formal written clinical policy, standing orders, patient recall/outreach, performance data shared at the provider/team-level, and performance data shared at the site/organization level. One intervention, the clinical champion, showed results in the "wrong" direction. We suspect this finding may have resulted from the fact that although a diabetes champion was in place, the individual was not a clinician. Data in subsequent years of the project will provide the opportunity for additional analyses related to these and other interventions.

Our results support the use of multicomponent interventions and are consistent with previous findings. ${ }^{14,17-21,32}$ Previous investigations have shown the effectiveness of some of the measures that were also found to be statistically significant in our project. For example, standing orders (eg, the direct authority of non-physician personnel to perform a task or function under pre-authorized written guidance from a physician) have been shown by others to effectively improve diabetes care. ${ }^{14,18}$ Also, the Alliance to Reduce Disparities in

Table 3 Percent of Patients with Poor Diabetes Control for Each Health Center, Georgia and lowa, During January 2017, December 2017, and the Average for the 12-Month Intervention

\begin{tabular}{|c|c|c|c|}
\hline Health Center Site & January & December & Average for 12-Month Interval \\
\hline 1 & $23.8 \%$ & $21.8 \%$ & $24.2 \%$ \\
\hline 2 & $55.5 \%$ & $24.6 \%$ & $44.0 \%$ \\
\hline 3 & $63.6 \%$ & $27.1 \%$ & $46.2 \%$ \\
\hline 4 & $70.4 \%$ & $36.4 \%$ & $63.5 \%$ \\
\hline Georgia & $53.3 \%$ & $27.5 \%$ & $44.5 \%$ \\
\hline 5 & $68.8 \%$ & $30.2 \%$ & $42.2 \%$ \\
\hline 6 & $70.1 \%$ & $29.3 \%$ & $41.8 \%$ \\
\hline 7 & $31.8 \%$ & $37.4 \%$ & $31.4 \%$ \\
\hline 8 & $23.7 \%$ & $13.6 \%$ & $16.2 \%$ \\
\hline lowa & $48.6 \%$ & $27.6 \%$ & $32.9 \%$ \\
\hline Overall & $50.9 \%$ & $27.5 \%$ & $38.7 \%$ \\
\hline
\end{tabular}


Table 4 Number of Months Each Intervention Was in Place, by Site

\begin{tabular}{|c|c|c|c|c|c|c|c|c|}
\hline \multirow[b]{2}{*}{ Type of Intervention } & \multicolumn{8}{|c|}{ Health Center Intervention Site } \\
\hline & $\mathbf{I}$ & 2 & 3 & 4 & 5 & 6 & 7 & 8 \\
\hline I. Written policy or procedure for diabetes & 12 & I & 1 & 8 & 1 & 8 & 1 & 12 \\
\hline 2. Standing orders for diabetes & 12 & 12 & 12 & 0 & 0 & 8 & 12 & 12 \\
\hline 3. Patient outreach/recall for diabetes & 12 & 7 & 0 & 0 & 2 & 8 & 0 & 12 \\
\hline 4. Performance data shared at provider/team-level & 12 & 12 & 0 & 0 & I & 12 & 12 & 12 \\
\hline 5. Performance data shared at site/health center-level & 12 & 12 & 12 & 12 & 5 & 12 & 12 & 12 \\
\hline 6. Clinical Champion for diabetes & 0 & 0 & 0 & 8 & 0 & 3 & 0 & 0 \\
\hline 7. Engaging in team huddles & 12 & 12 & 0 & 12 & 0 & 12 & 0 & 12 \\
\hline 8. Training staff in EHR diabetes care documentation & 3 & 0 & 0 & 2 & 0 & 4 & 0 & 12 \\
\hline 9. Cleaning up EHR documentation related to diabetes & 0 & 4 & 0 & 0 & 2 & 9 & 0 & 1 \\
\hline Average interventions per month & 6.3 & 5 & 2.1 & 3.5 & 0.9 & 6.3 & 3.1 & 7.1 \\
\hline
\end{tabular}

Abbreviation: EHR, electronic health record.

Diabetes reported that sharing data across care-providing organizations is especially important for diabetes control. ${ }^{31}$

Given the multi-faceted and complex nature of diabetes, we expected that several interventions applied at the same time would be necessary to influence outcomes. While we are not surprised by the factors which were shown to be significant, the results of our project point to an actionable pathway to accomplish multi-system changes within health centers that can result in improved diabetes control. These findings support earlier work on the potential impact of the NACHC VTF as a multi-modality QI and transformation approach for improving health outcomes. ${ }^{15}$

\section{Limitations}

This project was limited to eight health centers in two states. Other health centers that differ in size, geography, or patient populations may not be able to employ the exact actions taken by the health centers in this project. What makes this project unique, is the way we provided a standardized conceptual framework for systems change, where each health center could operationalize the evidence-based interventions recommended in ways that match their organizational culture, quality improvement systems, and resources. The overall project strategy is, therefore, standard and can be replicated. It included the three-pronged approach with the VTF, evidence-based system interventions, and the Learning Community Model. These same methods can be applied by any health center to effect transformation.

Data were self-reported by health centers using methods outlined in HRSA UDS reporting requirements. While it is possible to over- or under- estimate data, this was managed with routine check-ins by the project team of health center data collection, validation, and that any missing data are missing at random. Also, health centers defined HbA1c Poor Control for this project by using the annual UDS reporting requirements followed for HRSA reporting. Finally, we were not able to track the data patient-by-patient, so in some instances, counts are duplicated across months, and our estimates should be interpreted in that context. However, even with potential duplication, the statistically significant decreased proportion of patients with uncontrolled diabetes is a robust finding.

\section{Conclusion}

Diabetes remains one of the most common medical conditions among US adults. When not managed properly, diabetes has tremendous health, social, and economic impacts. This project documents a systems-wide, multi-faceted approach that can be adopted and adapted by health centers and shows promise for improving diabetes control and delivery of value-driven care. Our work suggests that health center systems-change driven by the NACHC Value Transformation Framework, deployed in a Learning Community model, can result in improved diabetes control at health centers.

\section{Acknowledgment}

Funder; NACHC has a cooperative agreement with the CDC: grant number: 6 NU380T000223-04-02. The authors thank the following health centers and primary care associations for their dedicated work in this project: Albany Area Primary Health Care, Albany, Georgia; Coastal Community Health Services, Brunswick, Georgia; Community Health Care 
Systems, Tennille, Georgia; East Georgia Healthcare Center, Swainsboro, Georgia; Community Health Centers of Southeastern Iowa, Burlington, Iowa; Eastern Iowa Health Center, Cedar Rapids, Iowa; Primary Health Care, Des Moines, Iowa; Community Health Centers of Southern Iowa, Leon, Iowa; Georgia Primary Care Association, Decatur, Georgia; and Iowa Primary Care Association, Des Moines, Iowa.

\section{Disclosure}

Joy H. Lewis and R. Curtis Bay report that they received grants from NACHC during the conduct of this project. Cheryl Modica reports grants from the Centers for Disease Control and Prevention, during the conduct of the study. The authors report no other potential conflicts of interest for this work.

\section{References}

1. US Department of Health and Human Services - Centers for Disease Control and Prevention. Division of diabetes translation at a glance; August 21, 2020. Available from: https://www.cdc.gov/chronicdisease/ resources/publications/aag/diabetes.htm. Accessed September 28, 2021.

2. US Department of Health and Human Services - Centers for Disease Control and Prevention. National diabetes statistics report 2020. Estimates of diabetes and its burden in the United States; 2020:32.

3. Diabetes Prevention Program Research Group. Reduction in the incidence of type 2 diabetes with lifestyle intervention or Metformin. $N$ Engl J Med. 2002;346(6):393-403. doi:10.1056/ NEJMoa012512.

4. American Diabetes Association. Standards of medical care in diabetes - 2019. Supplement 1; 2019:42. Available from: https://care. diabetesjournals.org/content/diacare/suppl/2018/12/17/42. Supplement_1.DC1/DC_42_S1_2019_UPDATED.pdf. Accessed January 27, 2021.

5. National Association of Community Health Centers. Community health center chartbook. NACHC; January, 2019. Available from: http://www. nachc.org/wp-content/uploads/2019/01/Community-Health-CenterChartbook-FINAL-1.28.19.pdf. Accessed August 10, 2019.

6. HRSA. Health Center Program: impact and Growth. Bureau of Primary Health Care; December, 2020. Available from: https://bphc. hrsa.gov/about/healthcenterprogram/index.html. Accessed January 8, 2021.

7. Goldman LE, Chu PW, Tran H, Stafford RS. Community health centers and private practice performance on ambulatory care measures. Am J Prev Med. 2012;43(2):142-149. doi:10.1016/j. amepre.2012.02.033

8. Ku LC, Richard P, Dor A, Tan E, Shin P, Rosenbaum SJ. Using primary care to bend the curve: estimating the impact of a health center expansion on health care costs. Himmelfarb Health Sci Libr; 2009.

9. Office of Disease Prevention and Health Promotion. Diabetes - 2020 topics \& objectives. Healthypeople.gov. Available from: https://www. healthypeople.gov/2020/topics-objectives/topic/diabetes. Accessed October 10, 2019.

10. Kochanek KD, Murphy SL, Xu J, Arias E. National vital statistics reports deaths: final data for 2017. Natl Vital Stat Rep. 2019;68(9):77.

11. Dieleman JL, Baral R, Birger M, et al. US spending on personal health care and public health, 1996-2013. JAMA. 2016;316 (24):2627-2646. doi:10.1001/jama.2016.16885
12. American Diabetes Association. Economic costs of diabetes in the U.S. in 2017. Diabetes Care. 2018;42(10):dci180007. doi:10.2337/ dci18-0007.

13. Gilmer TP, O'Connor PJ, Manning WG, Rush WA. The cost to health plans of poor glycemic control. Diabetes Care. 1997;20 (12):1847-1853. doi:10.2337/diacare.20.12.1847

14. Shojania KG, Ranji SR, McDonald KM, et al. Effects of quality improvement strategies for type 2 diabetes on glycemic control: a meta-regression analysis. JAMA. 2006;296(4):427-440. doi:10.1001/ jama.296.4.427

15. Modica C, Lewis JH, Bay C. Colorectal cancer: applying the value transformation framework to increase the percent of patients receiving screening in federally qualified health centers. Prev Med Rep. 2019;15:100894. doi:10.1016/j.pmedr.2019.100894

16. Haw JS, Narayan KMV, Ali MK. Quality improvement in diabetessuccessful in achieving better care with hopes for prevention. Ann N Y Acad Sci. 2015;1353(1):138-151. doi:10.1111/nyas.12950

17. Chin MH, Auerbach SB, Cook S, et al. Quality of diabetes care in community health centers. Am J Public Health. 2000;90 (3):431-434.

18. Pimouguet C, Le Goff M, Thiébaut R, Dartigues JF, Helmer C. Effectiveness of disease-management programs for improving diabetes care: a meta-analysis. Can Med Assoc J. 2011;183(2):E115E127. doi:10.1503/cmaj.091786

19. Tricco AC, Ivers NM, Grimshaw JM, et al. Effectiveness of quality improvement strategies on the management of diabetes: a systematic review and meta-analysis. Lancet. 2012;379(9833):2252-2261. doi:10.1016/S0140-6736(12)60480-2

20. Chin MH, Cook S, Jin L, et al. Barriers to providing diabetes care in community health centers. Diabetes Care. 2001;24(2):268-274. doi:10.2337/diacare.24.2.268

21. Peek ME, Cargill A, Huang ES. Diabetes health disparities: a systematic review of health care interventions. Med Care Res Rev. 2007;64(5Suppl):101S-56S. doi:10.1177/1077558707305409

22. Sikka R, Morath JM, Leape L. The quadruple aim: care, health, cost and meaning in work. BMJ Qual Saf. 2015;24(10):608-610. doi:10.1136/bmjqs-2015-004160

23. Feeley D. The triple aim or the quadruple aim? Four points to help set your strategy. Institute for Healthcare Improvement; 2017. Available from: http://www.ihi.org/communities/blogs/the-triple-aim-or-the-quadrupleaim-four-points-to-help-set-your-strategy. Accessed October 10, 2019.

24. Modica C. The value transformation framework: an approach to value-based care in federally qualified health centers. $J$ Healthc Qual. 2020;42(2):106-112. doi:10.1097/JHQ.0000000000000239

25. Haggstrom DA, Clauser SB, Taplin SH. The health disparities cancer collaborative: a case study of practice registry measurement in a quality improvement collaborative. Implement Sci IS. 2010;5 (1):42. doi:10.1186/1748-5908-5-42

26. Kilo CM. A framework for collaborative improvement: lessons from the institute for healthcare improvement's breakthrough series. Qual Manag Health Care. 1998;6(4):1-13. doi:10.1097/00019514199806040-00001

27. Wagner EH, Glasgow RE, Davis C, et al. Quality improvement in chronic illness care: a collaborative approach. Jt Comm J Qual Improv. 2001;27(2):63-80.

28. United States Census Bureau. 2010 census urban and rural classification and urban area criteria. The United States Census Bureau; December, 2019. Available from: https://www.census.gov/programssurveys/geography/guidance/geo-areas/urban-rural/2010-urban-rural. html. Accessed January 27, 2021.

29. Langley GJ, Moen RD, Nolan KM, Nolan TW, Norman CL, Provost LP. The Improvement Guide: A Practical Approach to Enhancing Organizational Performance. John Wiley \& Sons; 2009.

30. Health Resources and Services Administration. Uniform data system, reporting instructions for 2017 health center data; 2017:197. 
31. Clark NM, Quinn M, Dodge JA, Nelson BW. Alliance system and policy change: necessary ingredients for improvement in diabetes care and reduction of disparities. Health Promot Pract. 2014;15 (2 suppl):11S-22S. doi:10.1177/1524839914543829

32. Glazier RH, Bajcar J, Kennie NR, Willson K. A systematic review of interventions to improve diabetes care in socially disadvantaged populations. Diabetes Care. 2006;29(7):1675-1688. doi:10.2337/ dc05-1942
33. Uniform data system; reporting instructions for 2017 health center data. Bureau of Primary Health Care; 2017. Available from: https:// bphc.hrsa.gov/sites/default/files/bphc/datareporting/reporting/ 2017udsreportingmanual.pdf. Accessed September 28, 2021.

\section{Publish your work in this journal}

The Journal of Multidisciplinary Healthcare is an international, peerreviewed open-access journal that aims to represent and publish research in healthcare areas delivered by practitioners of different disciplines. This includes studies and reviews conducted by multidisciplinary teams as well as research which evaluates the results or conduct of such teams or healthcare processes in general. The journal covers a very wide range of areas and welcomes submissions from practitioners at all levels, from all over the world. The manuscript management system is completely online and includes a very quick and fair peer-review system. Visit http://www.dovepress.com/testimonials. php to read real quotes from published authors. 